\title{
The Simbla TURBT Simulator in Urological Residency Training: From Needs Analysis to Validation
}

Citation for published version (APA):

de Vries, A. H., van Genugten, H. G. J., Hendrikx, A. J. M., Koldewijn, E. L., Schout, B. M. A., Tjiam, I. M., van Merrienboer, J. J. G., Muiitjens, A. M. M., \& Wagner, C. (2016). The Simbla TURBT Simulator in Urological Residency Training: From Needs Analysis to Validation. Journal of Endourology, 30(5), 580587. https://doi.org/10.1089/end.2015.0723

Document status and date:

Published: 01/05/2016

DOI:

10.1089/end.2015.0723

Document Version:

Publisher's PDF, also known as Version of record

Document license:

Taverne

Please check the document version of this publication:

- A submitted manuscript is the version of the article upon submission and before peer-review. There can be important differences between the submitted version and the official published version of record.

People interested in the research are advised to contact the author for the final version of the publication, or visit the DOI to the publisher's website.

- The final author version and the galley proof are versions of the publication after peer review.

- The final published version features the final layout of the paper including the volume, issue and page numbers.

Link to publication

\footnotetext{
General rights rights.

- You may freely distribute the URL identifying the publication in the public portal. please follow below link for the End User Agreement:

www.umlib.nl/taverne-license

Take down policy

If you believe that this document breaches copyright please contact us at:

repository@maastrichtuniversity.nl

providing details and we will investigate your claim.
}

Copyright and moral rights for the publications made accessible in the public portal are retained by the authors and/or other copyright owners and it is a condition of accessing publications that users recognise and abide by the legal requirements associated with these

- Users may download and print one copy of any publication from the public portal for the purpose of private study or research.

- You may not further distribute the material or use it for any profit-making activity or commercial gain

If the publication is distributed under the terms of Article $25 \mathrm{fa}$ of the Dutch Copyright Act, indicated by the "Taverne" license above, 


\title{
The Simbla TURBT Simulator in Urological Residency Training: From Needs Analysis to Validation
}

\author{
Anna H. de Vries, MD, Hilde G.J. van Genugten, MD, Ad J.M. Hendrikx, MD, PhD, \\ Evert L. Koldewijn, MD, PhD, ${ }^{1,2}$ Barbara M.A. Schout, MD, PhD, ${ }^{3,4}$ Irene M. Tjiam, MD, PhD, ${ }^{4}$ \\ Jeroen J.G. van Merriënboer, PhD, ${ }^{2}$ Arno M.M. Muijtjens, PhD, ${ }^{6, *}$ and Cordula Wagner, PhD $^{4,7}$
}

\begin{abstract}
Objective: To investigate the value of the physical Simbla Transurethral Resection of a Bladder Tumor (TURBT) simulator as an educational tool within urological residency training, by means of a training needs analysis (TNA) and assessment of its feasibility, acceptability, and face, content, and construct validity.

Methods: To analyze the training needs for TURBT, procedural steps and pitfalls were identified and the TNA was completed during an expert consensus meeting. Participants $(n=76)$ were divided into three groups based on their experience in TURBT: novices, intermediates, and experts. Participants performed two standardized TURBT procedures on the simulator. Face validity and content validity, as well as feasibility and acceptability, were assessed with a quantitative survey. Construct validity was assessed by comparing the performance of novices, intermediates, and experts on resection time, quality of tumor resection, and overall performance.

Results: Of the 21 procedural steps and 17 pitfalls defined in TNA, 13 steps and 8 pitfalls were covered by the Simbla. Participants rated the Simbla's overall realism (face validity) with a score of 8 of 10 (range 6-9). The simulator was judged to be most useful (content validity) for learning eye-hand coordination: score 8 (6-10). All aspects regarding realism and usefulness were rated above the acceptability threshold of 6/10. Intermediates $(100 \%)$ and experts $(96 \%)$ considered the Simbla to be a useful educational tool within the urological curriculum. Resection time was longer for novices than for experts ( $p<0.05$; construct validity). In addition, the overall performance of novices was rated lower compared with intermediates and experts, and novices showed more irradical resections and bladder perforations (all $p<0.05$ ).

Conclusions: The Simbla TURBT simulator is a valid, feasible, and acceptable educational tool for training procedural skills and may be implemented in the urological curriculum to complement learning in clinical practice. TNA is valuable in defining training objectives and evaluating the educational value of a simulator.
\end{abstract}

\section{Introduction}

B LADDER CANCER IS the most common malignancy of the urinary tract, initially treated with Transurethral Resection of a Bladder Tumor (TURBT). ${ }^{1}$ The main goal of this procedure is to make a correct diagnosis and to remove all visible lesions. ${ }^{1}$ The TURBT is a technically challeng- ing procedure that demands high oncological accuracy as a complete and correct TURBT is essential to achieve a good prognosis. ${ }^{2}$ The presence of detrusor muscle in TURBT, a surrogate marker of quality, has appeared to be dependent on surgical experience. ${ }^{3}$ Moreover, surgical experience is associated with higher operative times and readmission rates and is predictive for recurrence after TURBT for Ta/T1 bladder

\footnotetext{
${ }^{1}$ Department of Urology, Catharina Hospital, Eindhoven, The Netherlands.

${ }^{2}$ School of Health Professions Education, Maastricht University, Maastricht, The Netherlands.

${ }^{3}$ Department of Urology, Alrijne Hospital, Leiden, The Netherlands.

${ }^{4}$ Netherlands Institute for Health Services Research (NIVEL), Utrecht, The Netherlands.

${ }^{5}$ Department of Urology, Radboud University Medical Center, Nijmegen, The Netherlands.

${ }^{6}$ Department of Educational Development and Research, Faculty of Health, Medicine and Life Sciences, Maastricht University, Maastricht, The Netherlands.

${ }^{7}$ Department of Public and Occupational Health, EMGO Institute for Health and Care Research, Amsterdam, The Netherlands.

*Dr. Arno M.M. Muijtjens was added as a coauthor. He performed the generalizability analysis and therefore made a significant contribution to this article.
} 
cancer. $^{4,5}$ Brausi and colleagues showed that a dedicated teaching program improves the quality of TURBT, reflected by a decrease in the complication rate and an increase in the presence of detrusor muscle. ${ }^{6}$

Simulation training is increasingly used in addition to the classical master-apprentice type of training to provide a safe and controlled environment for learning and preserving skills. ${ }^{7}$ Skills training on simulators can reduce the clinical training time by effectively advancing residents through their early learning curve. ${ }^{8,9}$ Ideally, simulation-based skills training should be incorporated into urological curricula, requiring residents to reach minimum proficiency on a simulator before being allowed to undertake surgical procedures in a supervised clinical setting. ${ }^{7}$

The first step in the development of procedural skills training should be to define the intended and desired outcomes of training. ${ }^{10}$ Training objectives, including procedural steps and pitfalls, can be identified by means of a training needs analysis (TNA), where the objectives close the gap between the actual needs of the learners and the desired outcomes of the training. ${ }^{11,12}$ Once the TNA has been established, a suitable simulator can be sought. Before incorporating this simulator into a urological curriculum, it should be validated to ensure that training on this simulator will actually enable residents to acquire the required operative skills. ${ }^{11,13,14}$

The aim of this study was to identify the training objectives for TURBT using a TNA and to assess the value of the Simbla TURBT simulator as an educational tool for achieving the objectives. We addressed the following research questions: What are the procedural steps and pitfalls of the TURBT procedure that should be used for training according to an expert panel? Is the Simbla a feasible and valid simulator for training these steps and avoiding these pitfalls to complement learning in clinical practice?

\section{Materials and Methods}

\section{Training needs analysis}

For the development of the TNA, a method was used that has been applied in military education and education in general for decades. ${ }^{15,16}$ Schout and colleagues have previously translated this method into three major steps to be used in urological practice: (1) description of general steps of the procedure based on expert opinion and international guidelines, (2) development of a general inventory of the most common (type and complexity) pitfalls of the procedure, and (3) detailed analysis of pitfalls in real-time procedure on patients. ${ }^{17}$ All procedural steps and technical and nontechnical pitfalls of TURBT were determined by two urologists and two residents. Subsequently, the composed framework was discussed during an expert consensus meeting with eight expert urologists, who were selected based on their extensive expertise in TURBT and their involvement in the training of urological residents. All experts were members of the European Association of Urology (EAU) and Dutch Society of Urology. They were assumed to be familiar with the EAU guidelines and, as such, these were also used at the time of the development. During the expert meeting, final consensus regarding the procedural steps was reached and additional technical and nontechnical pitfalls of the procedure were identified.

\section{Design and participants}

This prospective, observational, and comparative study was conducted in the urology departments of seven teaching hospitals across The Netherlands. Participants were recruited and divided into three groups based on their experience in TURBT: novices (residents with $<5$ TURBT procedures observed/assisted); intermediates (residents with $>5$ TURBT procedures observed/assisted, but $<50$ TURBT procedures performed independently), and experts (urologists with more than 50 TURBT procedures performed independently). All participants received a verbal introduction on the use of the simulator, which was provided by two tutors (HvG and $\mathrm{HdV}$ ). $\mathrm{HvG}$ gave the instructions in the first three hospitals, and $\mathrm{HdV}$ provided the instructions in the remaining four hospitals. To ensure identical instructions, an instruction form was used. Furthermore, HdV attended four procedures in which the explanation was provided by $\mathrm{HvG}$.

The participants performed two standardized TURBT procedures. Standardization was incorporated to enable a reliable comparison of performance between novices, intermediates, and experts. This included the use of identical bladder substrates and a predefined order of tumor resection (bladder map; Supplementary Fig. S1; Supplementary Data are available online at www.liebertpub.com/end). Before the start of the procedure, the tutor showed the bladder map and explained the order of resection. The participants were instructed to perform a complete tumor resection and to resect the tumors until 2 to $3 \mathrm{~mm}$ below the surface of the bladder wall. No further information was given on the procedural steps or on how to conduct the procedure from the beginning to the end. The tutor was present throughout the procedure and performance was recorded on video to enable video assessment. Video recordings consisted of external views in combination with endoscopic views.

\section{The simulator}

The Simbla TURBT simulator (SAMED GmbH, Dresden, Germany) is a high-fidelity physical simulator that consists of a basic unit (Resection-Trainer LS10-31 2.0.) in which the Simbla operation case is placed (Fig. 1). In this

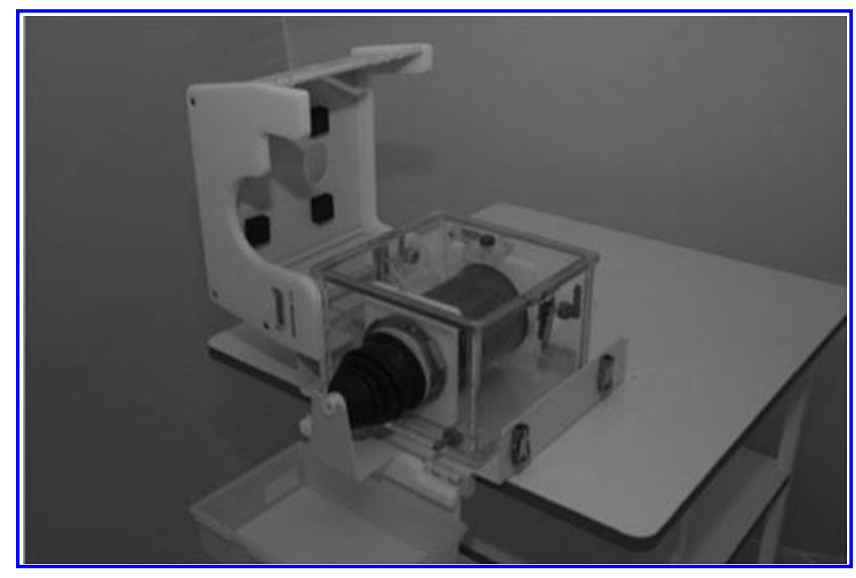

FIG. 1. Simbla TURBT simulator (Samed GmbH, Dresden, Germany). Simbla TURBT simulator, copyright: Samed $\mathrm{GmbH}$. 
operation case, a bladder substrate that consists of resectionable material is inserted. The bladder substrate includes anatomical structures (bladder base, ureteral orifices) and embedded tumors. The simulator is used with real-life instruments and monopolar or bipolar diathermy to resect the tumors. The basic unit and resectoscope are connected to an irrigation system that enables continuous flow through the system. All participants performed the resection using bipolar diathermy.

\section{Outcome parameters}

Immediately after performance of the task, participants completed a questionnaire to collect data on general demographics, face validity, and content validity, as well as feasibility and acceptability. Question formats included multiple choice, grading on a 10-point Likert scale $(1=$ not at all realistic/useful, $10=$ highly realistic/useful), and open-ended questions. A copy of the questionnaire can be obtained from the primary author on readers' request.

Outcome parameters used to evaluate construct validity included resection time, quality of tumor resection, and assessment of overall performance. Quality of tumor resection was reflected by radicality of tumor resection and the presence of a bladder perforation. This was assessed by an expert urologist who critically inspected all physical bladder substrates using a light torch to ensure an optimal view. As participants were instructed to perform a complete tumor resection until 2 to $3 \mathrm{~mm}$ below the surface of the bladder wall, the resection was judged to be incomplete if the slightest residual tumor tissue was visible. The bladder substrate did not exactly simulate the anatomical layers of the bladder; however, it was possible to objectify a perforation since the tissue turns red when the resection is too deep. Examples of an incomplete resection and a perforation are shown in Supplementary Fig. S2.

Based on video recordings, the overall performance was judged by two independent expert urologists per participant, who were blinded for training status. The expert urologists (eight urologists in total) were instructed to rate the overall performance on a 10-point Likert scale and to include all aspects of the TNA in their general judgment. To optimize the inter-rater reliability $(I R R)$, an assessor meeting was conducted before the video assessment. In this meeting, two TURBT procedures of a novice participant and two procedures of an expert participant were viewed and assessed. Consequently, the assessment results were discussed until consensus was reached.

\section{Statistical analyses}

To investigate the IRR of the two examiners on the assessment of overall performance, a generalizability analysis was performed for this variable. ${ }^{18}$ For each of the two cases, a different pair of raters assessed a participant's performance. Per case, each pair of raters assessed a set of 16 to 21 participants, resulting in a set of performance rating pairs. Using this setup, with two cases and four pairs of raters, $2 \times 4=8$ sets of performance rating pairs resulted. For each set, a separate G-analysis was performed, using a participant $\times$ rater model resulting in estimates of the variance components (VCs) $V p$ (between-participant variance), $V r$ (between-rater variance), and $V p \times \mathrm{r}$ (person-rater interaction variance). $V p$ is the variance of interest, and $V r$ and $V p \times \mathrm{r}$ represent the measurement error VCs. For each VC, the average value over the eight participant groups was obtained, and based on these values, the IRR was calculated according to the following expression:

$$
I R R=\frac{V_{p}}{V_{p}+\left(V_{\mathrm{r}}+V_{p \times \mathrm{r}}\right) / N_{r}},
$$

where $N r$ is the number of raters per participant-case combination, which in the current setup, was equal to 2 . An IRR of 0.80 or higher may be considered to indicate adequate interrater agreement. ${ }^{19}$

Comparisons between groups (novice-intermediate-expert) were analyzed using the Mann-Whitney $U$-test (continuous variables) or the chi-square test (categorical variables). A $p$-value $<0.05$ was considered statistically significant. Analyses were performed using the software package, IBM SPSS Statistics, version 20.0.

\section{Ethics}

Ethical approval was sought from the institutions' research and ethics committee. They ruled that ethical approval was not required, according to the Dutch Medical Research (Human Subjects) Act, since no patients or patient details were involved. Written informed consent with assurance of anonymity and confidentiality was obtained from all participants before the start of the procedure.

\section{Results}

Between February and July 2015, a total of 76 participants were included in this study: novices $(n=25)$, intermediates $(n=26)$, and experts $(n=25)$. The general demographics are described in Table 1.

\section{Training needs analysis}

The TNA resulted in a detailed document for whole task training in TURBT. Table 2 presents the 21 identified procedural steps and Table 3 gives an overview of the 17 technical and nontechnical pitfalls. Both tables include the assumption of whether the Simbla simulator is able to simulate (parts of) the procedural steps and pitfalls. A total of 13

Table 1. General Demographics

\begin{tabular}{lccc}
\hline & $\begin{array}{c}\text { Novices } \\
(\mathrm{n}=25)\end{array}$ & $\begin{array}{c}\text { Intermediates } \\
(\mathrm{n}=26)\end{array}$ & $\begin{array}{c}\text { Experts } \\
(\mathrm{n}=25)\end{array}$ \\
\hline $\begin{array}{l}\text { Age (year) } \\
\text { Gender (M/F) }\end{array}$ & $28(25-35)$ & $32(29-38)$ & $49(32-64)$ \\
$\begin{array}{l}\text { Dexterity } \\
\text { (right/left) }\end{array}$ & $21 / 4$ & $13 / 13$ & $23 / 2$ \\
$\begin{array}{l}\text { Experience } \\
\text { in TURBT } \\
\text { (independently }\end{array}$ & $0(0)$ & $4(0-38)$ & $100(50-500)$ \\
performed) & & & \\
\hline
\end{tabular}

Values for variables (age and experience in TURBT) are presented as medians with range.

TURBT $=$ Transurethral Resection of a Bladder Tumor 
Table 2. Training Needs Analysis: PROCEDURAL STEPS

\begin{tabular}{|c|c|}
\hline Procedural steps & $\begin{array}{c}\text { Simbla } \\
(+/-)\end{array}$ \\
\hline \multicolumn{2}{|l|}{ Preparatory phase } \\
\hline $\begin{array}{l}\text { Check patient-related details (correct patient, } \\
\text { indication, allergies, culture, antibiotics, } \\
\text { anticoagulants, n.obt block) }\end{array}$ & - \\
\hline $\begin{array}{l}\text { Check material-related details (equipment } \\
\text { up to date, presence of materials, settings } \\
\text { diathermy, irrigation fluid) }\end{array}$ & - \\
\hline $\begin{array}{l}\text { Patient preparation (positioning, bimanual } \\
\text { examination, disinfection, sterile drapes) }\end{array}$ & - \\
\hline \multicolumn{2}{|l|}{ Procedural phase } \\
\hline Assembling instruments and connecting tubes & + \\
\hline $\begin{array}{l}\text { Adjustment of light settings, focus camera, } \\
\text { white balance }\end{array}$ & + \\
\hline $\begin{array}{l}\text { Instillation of lubricant into meatus and final } \\
\text { end obturator }\end{array}$ & $+/-$ \\
\hline Introduction resectoscope & + \\
\hline $\begin{array}{l}\text { Inspection bladder, including orientation, } \\
\text { identification of orifices, and bladder tumors }\end{array}$ & + \\
\hline Tumor resection & + \\
\hline Tissue evacuation & + \\
\hline Judgment of end result & + \\
\hline \multicolumn{2}{|l|}{ Continuous variables procedural phase } \\
\hline Change of instruments during procedure & + \\
\hline Orientation in the bladder & + \\
\hline Regulation of irrigation and emptying bladder & - \\
\hline Hemostasis & - \\
\hline \multicolumn{2}{|l|}{ Completion phase } \\
\hline Removal of instruments & + \\
\hline Bimanual examination & - \\
\hline Introduction of transurethral catheter & + \\
\hline $\begin{array}{l}\text { Check drainage and connect continuous } \\
\text { flow system }\end{array}$ & $+1-$ \\
\hline $\begin{array}{l}\text { Debriefing (check count materials and tissue } \\
\text { collection, discussion complications, and } \\
\text { postoperative policy) }\end{array}$ & - \\
\hline $\begin{array}{l}\text { Registration (operating report, pathology file, } \\
\text { patient file, financial registration) }\end{array}$ & - \\
\hline
\end{tabular}

+/-: the assumption of whether or not the procedural steps can be (partially) trained on the Simbla TURBT simulator.

of 21 procedural steps and 8 of 17 technical and nontechnical pitfalls were judged to be covered by the Simbla simulator.

\section{Realism and usefulness of the Simbla: face validity and content validity}

Figure 2 presents the results of the evaluation of face validity (realism) and content validity (usefulness), as perceived by intermediates and experts. Responses of the novice group were excluded due to their inexperience. The overall realism was median 8 on the 10-point scale (range 6-9). The simulator was judged to be most useful in learning eye-hand coordination (score 8 [6-10]) and least useful in learning to avoid complications (score 6.5 [3-9]). All aspects of the simulator were rated above the acceptability threshold of 6 of $10,{ }^{20}$ clearly demonstrating face validity and content validity of this simulator. No differences were found be-
Table 3. Training Needs Analysis: Technical and Nontechnical Pitfalls

Pitfalls $\begin{gathered}\text { Simbla } \\ (+/)\end{gathered}$

Technical pitfalls

Eye-hand coordination

Orientation of the camera

Haptic feedback

Strokes inadequate (too short/incomplete)

Visual check of depth resection (presence detrusor)/ability to check resection depth

Bladder perforation

Coagulation in/around ureteral orifices

Obturator kick

Loss of foot pedal (press cut instead of coagulate)

Failure to empty the bladder on time

Postoperative check drainage of catheter

Nontechnical pitfalls

Insufficient procedural knowledge

Insufficient knowledge of materials/electrosurgery

Insufficient preparation

Insufficient/incorrect communication

Total resection time too long (risk TUR-syndrome)

Lack of recognition/anticipation/ handling of complications (bleeding/perforation/TUR-syndrome)

$+/-$ : the assumption of whether or not the pitfalls can be (partially) trained on the Simbla TURBT simulator.

tween the ratings of intermediates $v s$ experts. The most frequently mentioned limitation of the simulator was a lack of bleeding, which precluded learning how to deal with limited sight.

\section{Feasibility and acceptability}

All intermediates and $96 \%$ of experts considered the Simbla to be a useful educational tool within the urological residency training program. The majority ( $84 \%$ of intermediates and $92 \%$ of experts) agreed that the simulator would be useful in assessing residents' technical skills before granting privileges for the independent performance of TURBT. The implementation of a summative TURBT assessment as a certification method for final year residents was supported by $42 \%$ of intermediates and $67 \%$ of experts.

\section{Construct validity}

Table 4 shows the results of the construct validity, assessing the simulator's ability to differentiate between different levels of experience. In both TURBT cases, experts had significantly shorter resection times than novices $(p=0.04$ and $p=0.03$ for case 1 and 2, respectively). Novices caused more bladder perforations than intermediates $(p=0.007$ and $p=0.002)$ and experts $(p=0.002$ and $p=0.06)$. In addition, novices showed more irradical tumor resections during the first procedure than intermediates $(p=0.04)$ and experts 
FIG. 2. Assessment of face and content validity of the Simbla TURBT simulator by intermediates and experts. Values for variables are presented as medians (10-point Likert scale, 1: not at all realistic/useful; 10: very realistic/useful).

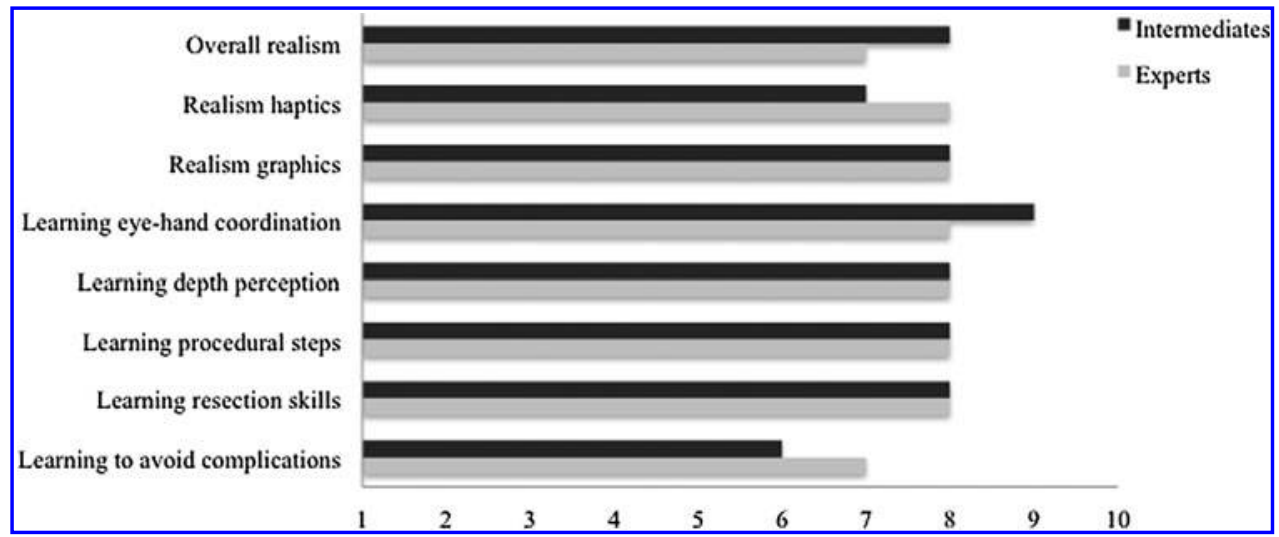

$(p=0.05)$. Finally, overall performance of novices was rated significantly lower for both procedures than intermediates (both $p$-values <0.001) and experts (both $p$-values $<0.001$ ), and intermediates scored significantly lower on overall performance than experts (both $p$-values $=0.02$ ).

\section{Inter-rater agreement}

The IRR for the overall performance as rated by the two assessors was found to be 0.81 , indicating an adequate interrater agreement.

\section{Discussion}

The present study showed that the Simbla TURBT simulator is a feasible and acceptable educational tool for procedural skills training in TURBT to complement training in clinical practice. Face validity, content validity, and construct validity of the simulator were clearly established. The performance of a TNA is valuable in defining training objectives and evaluating the educational value of a simulator within a curriculum.
Face validity and content validity of the Simbla were confirmed as all items of the survey relating to its realism and usefulness were rated above the acceptability threshold of 6 of $10 .^{20}$ Unfortunately, a simulator will never be able to simulate the real situation completely. The most important limitation of the Simbla was its inability to simulate bleeding, which is a vital aspect of the TURBT procedure. Despite this limitation, the vast majority of participants considered the simulator to be a useful educational tool to complement learning in clinical practice. In simulation-based training, it is paramount that the simulator serves the goal of training. If the goal of training would be to train the basic skills of a TURBT procedure (e.g., procedural steps, eye-hand coordination, resections skills), the Simbla would be perfectly suitable. However, if the goal of TURBT training would be primarily hemostasis and learning to deal with limited visibility, another simulator should be sought.

Besides establishing face validity and content validity, which are subjective methods for assessing the simulator, a more objective assessment also requires evaluation of construct, concurrent, and predictive validity. ${ }^{21,22}$ Construct validity was evaluated by comparing the performance of

Table 4. Assessment of Construct Validity of the Simbla tURBT Simulator

\begin{tabular}{|c|c|c|c|c|c|c|}
\hline & Novices & Intermediates & Experts & $\mathrm{p}(N$ vs $I)$ & $\mathrm{p}(I$ vs $E)$ & $\mathrm{p}(N$ vs $E)$ \\
\hline \multicolumn{7}{|l|}{ Time } \\
\hline TURBT 1: time (s) & $92.5(46-286)$ & $80(14-286)$ & $64(30-131)$ & 0.17 & 0.48 & 0.04 \\
\hline TURBT 2: time (s) & $100(49-262)$ & $76(26-177)$ & $74(30-157)$ & 0.08 & 0.93 & 0.03 \\
\hline \multicolumn{7}{|l|}{ Quality of resection } \\
\hline $\begin{array}{l}\text { TURBT 1: incomplete } \\
\text { resection }(\%)\end{array}$ & 60 & 31 & 32 & 0.04 & 0.93 & 0.05 \\
\hline $\begin{array}{l}\text { TURBT 2: incomplete } \\
\text { resection }(\%)\end{array}$ & 36 & 35 & 48 & 0.92 & 0.33 & 0.39 \\
\hline TURBT 1: perforation (\%) & 40 & 8 & 4 & 0.007 & 1 & 0.002 \\
\hline TURBT 2: perforation (\%) & 40 & 4 & 16 & 0.002 & 0.19 & 0.06 \\
\hline \multicolumn{7}{|c|}{ Overall performance $(1=$ min.; $10=\max )}$. \\
\hline TURBT 1 & $3.5(2-7)$ & $7.0(2-9)$ & $7.5(5-9)$ & $<0.001$ & 0.02 & $<0.001$ \\
\hline TURBT 2 & $5.0(3-8)$ & $7.0(4-8)$ & $8.0(6-9)$ & $<0.001$ & 0.02 & $<0.001$ \\
\hline
\end{tabular}

Values for variables are presented as medians (min.-max.) and percentages per group (novices, intermediates, experts).

Individual overall performance of TURBT 1 and TURBT 2 was judged by two expert urologists, and the mean of these two values was calculated. The reflected value is the median value of the mean overall performance per group (novices, intermediates, experts).

Bold values represent significant differences.

$\mathrm{E}=$ experts; $\mathrm{I}=$ intermediates; $\mathrm{N}=$ novices. 
novices, intermediates, and experts on several outcome parameters. In this study, these parameters were determined based on the results of the TNA to ensure that the skills to be assessed would be relevant for clinical practice. ${ }^{17,23}$ The most vital outcome parameter was overall performance as this parameter provides a general judgment regarding all the aspects of TURBT that were included in the TNA. The overall performance for novices was rated lower than the overall performance of intermediates and experts, and between intermediates and experts, which reflects the ability of the simulator to differentiate between different levels of experience. Remarkably, there were no significant differences in the quality of resection performed by intermediates $v s$ experts. This could indicate that the simulator is most suitable for residents in the beginning of their learning curve. To confirm that the performance of novices is improved with repeated sessions on the simulator, it would be interesting to conduct a learning curve study with novices. This will be a topic for a future study.

The results regarding incomplete resection and perforation of the second TURBT procedure (novices $v s$ experts) are remarkable. The novices showed a decrease in percentage of incomplete resection and a similar percentage of perforation, whereas both parameters were increased in the expert group. This difference cannot be explained by the case difficulty as this was kept constant in both cases with a similar location of the tumors to be resected (bladder map; Supplementary Fig. S1; Supplementary Data are available online at www.liebertpub.com/end). A possible explanation could be that the expert group was less thorough and precise during the second procedure due to their heavy workload, forcing them to finish the session in an untimely manner. The total inclusion took $\sim 1$ hour, and it was a challenge to fit this in their busy schedule. This problem is likely to be less apparent in the motivated novice and intermediate groups.

A recent review on simulation in urological training presented an overview of the available simulators and their validation status. ${ }^{24}$ For TURBT, only two simulators were described: a virtual reality (VR) simulator (URO-mentor; Simbionix) and a Bench model (limbs and things). Face validity, content validity, and construct validity were demonstrated for the URO-mentor. ${ }^{24}$ To our knowledge, this study is the first one to validate a physical TURBT simulator (i.e., the Simbla). An advantage of a physical simulator over a VR simulator is that real instruments and irrigation can be used. Furthermore, the haptic feedback of the Simbla was judged to be realistic, something that has appeared to be technically difficult to simulate in a VR simulator. ${ }^{25,26}$ Therefore, the validated Simbla simulator could become a valuable educational tool for simulation-based skills training in TURBT.

The approach of validating simulators has been extensively discussed in the literature, but universally accepted criteria on how to validate simulators are still lacking. ${ }^{17} \mathrm{Up}$ till now, the majority of validation studies have focussed on the validation of individual simulators. ${ }^{27,28}$ However, it is increasingly recognized that simulation should not be used as a stand-alone tool for education, but rather be integrated into a comprehensive curriculum. ${ }^{9,11}$ By conducting a TNA, the required skills and training objectives of a certain procedure can be identified, and consequently the suitability of a simulator in achieving these training objectives can be evaluated. ${ }^{11}$ It should be emphasized that a simulator does not have to cover all procedural steps and pitfalls of a certain procedure to be suitable for simulation-based skills training. As Brewin and colleagues stated, "a simulator must replicate the operative environment well enough to transfer appropriate skills, but high-fidelity simulation is not always required to achieve this." 21 In the future, the checklist resulting from TNA could be used as a formative assessment tool in clinical practice. This would generate constructive individual feedback and measure the individual training needs. For the development of a summative assessment tool that can be used in the certification of residents and urologists, a constructive methodology such as cognitive task analysis (CTA) is more suitable. ${ }^{29}$ CTA aims to capture knowledge, procedural steps, thought processes, and decision-making during performance of a complex task to identify conscious and unconscious skills. ${ }^{30-32}$ As experts have automated parts of their performance, they are no longer conscious of every step they take and have difficulties in identifying these points where certain decisions are made. ${ }^{30,33,34}$ CTA offers a unique educational method to deconstruct the automated skills of experts and to identify relevant steps and decision points. ${ }^{35}$ The use of this methodology could lead to a summative assessment tool that encompasses technical as well as nontechnical (cognitive) skills.

For implementation of skills training on the Simbla TURBT simulator within urological residency training, several logistic and financial issues need to be taken into account. For the training, $\sim 1$ hour is required. Ideally, a supervising urologist should be (partly) present to provide direct feedback. Another option would be to record the training on video and discuss the resident's performance afterward. The simulator (Fig. 1) should be placed on a table and real-life instruments and equipment can be used. This means that the training can proceed at the operating room, the outpatient department, or in a skills laboratory. The price of the simulator is $€ 3309,00$, and the disposable bladder substrates cost $€ 62,00$ per piece. The costs of the disposable bladder substrates are the only ongoing costs of the Simbla TURBT training, in which one bladder substrate can be used by one or two residents.

A limitation of this study is that a power calculation was not performed before the start of the study. Instead, the number of included participants was based on a similar previous study, in which $3 \times 22$ participants were included for the validation of a TURP simulator. ${ }^{11}$ Regarding the development of the TNA, expert opinion on the procedural steps of TURBT was assumed to take international guidelines into account, yet these guidelines were not taken as a starting point. When retrospectively comparing the results of the TNA with the procedural steps that are described in the current EAU guideline (nonmuscle invasive bladder cancer), all procedural steps of the guideline are included in the TNA and some detailed information is added. However, in the performance of future TNAs, it might be superior to use the guidelines as a starting point.

Finally, predictive validity, assessing the effect of training on a simulator on real-time OR performance, was not yet evaluated. This is an important aspect since the establishment of predictive validity could result in a more reliable conclusion regarding the transferability of skills from the Simbla to the operating room. Assessment of predictive validity will be a topic for future study, in which training on the Simbla is followed by assessment of performance in the operating 
room, preferably using a standardized, validated assessment tool developed by means of CTA.

\section{Conclusions}

The Simbla TURBT simulator was considered to be a feasible and acceptable educational tool for training procedural skills. Face validity, content validity, and construct validity were clearly established in this study. The Simbla may be implemented in the urological curriculum to complement learning in clinical practice. TNA is valuable in defining training objectives and evaluating the educational value of a simulator within a curriculum.

\section{Acknowledgments}

The authors gratefully acknowledge all residents and urologists who participated in this study. The authors also would like to thank Dr. Saskia Houterman for statistical advice and Lisette van Hulst for editorial assistance.

\section{Author Disclosure Statement}

No competing financial interests exist.

\section{References}

1. Babjuk M, Burger M, Zigeuner R, et al. EAU guidelines on non-muscle-invasive urothelial carcinoma of the bladder: Update 2013. Eur Urol 2013;64:639-653.

2. Brausi M, Collette L, Kurth K, et al. Variability in the recurrence rate at first follow-up cystoscopy after TUR in stage Ta T1 transitional cell carcinoma of the bladder: A combined analysis of seven EORTC studies. Eur Urol 2002; 41:523-531.

3. Mariappan P, Zachou A, Grigor KM, et al. Detrusor muscle in the first, apparently complete transurethral resection of bladder tumour specimen is a surrogate marker of resection quality, predicts risk of early recurrence, and is dependent on operator experience. Eur Urol 2010;57:843-849.

4. Jancke G, Rosell J, Jahnson S. Impact of surgical experience on recurrence and progression after transurethral resection of bladder tumour in non-muscle-invasive bladder cancer. Scand J Urol 2014;48:276-283.

5. Roupret M, Yates DR, Varinot J, et al. The presence of detrusor muscle in the pathological specimen after transurethral resection of primary pT1 bladder tumors and its relationship to operator experience. Can J Urol 2012;19: 6459-6464.

6. Brausi M, Gavioli M, Peracchia Gea. Dedicated teaching programs can improve quality of TUR on non-muscle invasive bladder tumours (NMIBT): Experience of a single institution. Eur Urol Suppl 2008;7:180 (abstract 437).

7. Forster JA, Browning AJ, Paul AB, et al. Surgical simulators in urological training-Views of UK Training Programme Directors. BJU Int 2012;110:776-778.

8. Arora S, Lamb B, Undre S, et al. Framework for incorporating simulation into urology training. BJU Int 2011;107: 806-810.

9. Ahmed K, Jawad M, Abboudi M, et al. Effectiveness of procedural simulation in urology: A systematic review. J Urol 2011;186:26-34.
10. Sweet RM, Hananel D, Lawrenz F. A unified approach to validation, reliability, and education study design for surgical technical skills training. Arch Surg 2010;145: 197-201.

11. Tjiam IM, Berkers CH, Schout BM, et al. Evaluation of the educational value of a virtual reality TURP simulator according to a curriculum-based approach. Simul Healthc 2014; 9:288-294.

12. Schout BM, Bemelmans BL, Martens EJ, et al. How useful and realistic is the uro trainer for training transurethral prostate and bladder tumor resection procedures? J Urol 2009;181:1297-1303; discussion 1303.

13. Ahmed K, Miskovic D, Darzi A, et al. Observational tools for assessment of procedural skills: A systematic review. Am J Surg 2011;202:469-480.e6.

14. McDougall EM. Validation of surgical simulators. J Endourol 2007;21:244-247.

15. Peyton J. Teaching and Learning in Medical Practice. Rickmansworth, UK: Manticore Europe Limited, 1998.

16. Dent J, Harden R. A Practical Guide for Medical Teachers. Dundee, UK: Elsevier Limited, 2005.

17. Schout BM, Hendrikx AJ, Scheele F, et al. Validation and implementation of surgical simulators: A critical review of present, past, and future. Surg Endosc 2010;24: 536-546.

18. Brennan RL. Generalizability Theory. New York: Springer Verlag, 2001.

19. Fraenkel JR, Wallen NE. How to Design and Evaluate Research in Education. 7th ed. Boston: McGraw Hill, 2009.

20. Sweet R, Kowalewski T, Oppenheimer P, et al. Face, content and construct validity of the University of Washington virtual reality transurethral prostate resection trainer. J Urol 2004;172:1953-1957.

21. Brewin J, Nedas T, Challacombe B, et al. Face, content and construct validation of the first virtual reality laparoscopic nephrectomy simulator. BJU Int 2010;106:850-854.

22. Van Nortwick SS, Lendvay TS, Jensen AR, et al. Methodologies for establishing validity in surgical simulation studies. Surgery 2010;147:622-630.

23. Zevin B, Levy JS, Satava RM, et al. A consensus-based framework for design, validation, and implementation of simulation-based training curricula in surgery. J Am Coll Surg 2012;215:580-586.e3.

24. Brewin J, Ahmed K, Challacombe B. An update and review of simulation in urological training. Int J Surg 2014;12: 103-108.

25. Chmarra MK, Dankelman J, van den Dobbelsteen JJ, et al. Force feedback and basic laparoscopic skills. Surg Endosc 2008;22:2140-2148.

26. Vapenstad C, Hofstad EF, Lango T, et al. Perceiving haptic feedback in virtual reality simulators. Surg Endosc 2013; 27:2391-2397.

27. Bright E, Vine S, Wilson MR, et al. Face validity, construct validity and training benefits of a virtual reality TURP simulator. Int J Surg 2012;10:163-166.

28. Aydin A, Ahmed K, Brewin J, et al. Face and content validation of the prostatic hyperplasia model and holmium laser surgery simulator. J Surg Educ 2014;71:339344.

29. van Merrienboer JJG, Kirschner PA. Ten Steps to Complex Learning. A Systematic Approach to Four-Component Instructional Design. New York/London: Routledge, 2013, pp. $78-111$. 
30. Clark R, Feldon D, van Merrienboer J, et al. Cognitive Task Analysis: Handbook of Research on Educational Communications and Technology. New York, NY: Taylor and Francis Group, 2008, pp. 577-593.

31. Yates K, Feldon D. Advancing the practice of cognitive task analysis: a call for taxonomic research. Theor Issues Ergon Sci 2011;12:1464-1536.

32. Salas E, Cannon-Bowers JA. The science of training: A decade of progress. Annu Rev Psychol 2001;52:471499.

33. Clark R, Estes F. Cognitive task analysis for training. Int J Educ Res 1996;25:403-417.

34. Gagne E, Yekovich C, Yekovich FR. Cognitive Psychology of School Learning, New York: Harper Collins, 1993.

35. Sullivan ME, Ortega A, Wasserberg N, et al. Assessing the teaching of procedural skills: Can cognitive task analysis add to our traditional teaching methods? Am J Surg 2008; 195:20-23.
Address correspondence to: Anna H. de Vries, MD Department of Urology Catharina Hospital Michelangelolaan 2 Eindhoven 5623 EJ The Netherlands

E-mail: a.h.de.vries@hotmail.com

$\begin{aligned} & \text { Abbreviations Used } \\ \mathrm{CTA}= & \text { cognitive task analysis } \\ \mathrm{EAU}= & \text { European Association of Urology } \\ \mathrm{IRR}= & \text { inter-rater reliability } \\ \mathrm{TURBT}= & \text { Transurethral Resection of a } \\ & \quad \text { Bladder Tumor } \\ \mathrm{TNA}= & \text { training needs analysis } \\ \mathrm{VC}= & \text { variance component } \\ \mathrm{VR}= & \text { virtual reality }\end{aligned}$




\section{This article has been cited by:}

1. Eunjin Choi, Frank Waldbillig, Moonkwang Jeong, Dandan Li, Rahul Goyal, Patricia Weber, Arkadiusz Miernik, Britta Grüne, Simon Hein, Rodrigo Suarez-Ibarrola, Maximilian Christian Kriegmair, Tian Qiu. 2021. Soft Urinary Bladder Phantom for Endoscopic Training. Annals of Biomedical Engineering 49:9, 2412-2420. [Crossref]

2. Frank Waldbillig, Lennard von Rohr, Malin Nientiedt, Britta Grüne, Simon Hein, Rodrigo Suarez-Ibarrola, Arkadiusz Miernik, Manuel Ritter, Maximilian C. Kriegmair. 2021. Endourological Training Using 3D-Printed Bladder Phantoms: Development and Prospective Evaluation. Journal of Endourology 35:8, 1257-1264. [Abstract] [Full Text] [PDF] [PDF Plus] [Supplementary Material]

3. Victor M. Schuettfort, Benjamin Pradere, Eva Compérat, Mohammad Abufaraj, Shahrokh F. Shariat. 2021. Novel transurethral resection technologies and training modalities in the management of nonmuscle invasive bladder cancer: a comprehensive review. Current Opinion in Urology 31:4, 324-331. [Crossref]

4. Rikke Langebæk, Mette Berendt, Andrea Tipold, Simon Engelskirchen, Marc Dilly. 2021. Evaluation of the Impact of Using a Simulator for Teaching Veterinary Students Cerebrospinal Fluid Collection: A Mixed-Methods Study. Journal of Veterinary Medical Education 48:2, 217-227. [Crossref]

5. Sławomir Poletajew, Wojciech Krajewski, Krystian Kaczmarek, Bartłomiej Kopczyński, Remigiusz Stamirowski, Andrzej Tukiendorf, Romuald Zdrojowy, Marcin Słojewski, Piotr Radziszewski. 2020. The Learning Curve for Transurethral Resection of Bladder Tumour: How Many is Enough to be Independent, Safe and Effective Surgeon?. Journal of Surgical Education 77:4, 978. [Crossref]

6. Brandon S. Childs, Marc D. Manganiello, Ruslan Korets. 2019. Novel Education and Simulation Tools in Urologic Training. Current Urology Reports 20:12. . [Crossref]

7. Jeremy Yuen-Chun Teoh, Chak-Lam Cho, Yong Wei, Shuji Isotani, Ho-Yee Tiong, Teng-Aik Ong, Kittinut Kijvikai, Peggy Sau-Kwan Chu, Eddie Shu-Yin Chan, Chi-Fai Ng. 2019. A newly developed porcine training model for transurethral piecemeal and en bloc resection of bladder tumour. World Journal of Urology 37:9, 1879-1887. [Crossref]

8. Gerald B. Schulz, Tobias Grimm, Alexander Buchner, Friedrich Jokisch, Jozefina Casuscelli, Alexander Kretschmer, Jan-Niclas Mumm, Brigitte Ziegelmüller, Christian G. Stief, Alexander Karl. 2019. Validation of a High-End Virtual Reality Simulator for Training Transurethral Resection of Bladder Tumors. Journal of Surgical Education 76:2, 568-577. [Crossref]

9. Wesley Baas, Bradley Schwartz. Simulation in Urology 289-317. [Crossref]

10. Zichen Zhao, Robert M. Sweet. Endoscopic Training/Simulation 159-172. [Crossref]

11. Anna H. de Vries, Arno. M. M. Muijtjens, Hilde G. J. van Genugten, Ad. J. M. Hendrikx, Evert L. Koldewijn, Barbara M. A. Schout, Cees P. M. van der Vleuten, Cordula Wagner, Irene M. Tjiam, Jeroen J. G. van Merriënboer. 2018. Development and validation of the TOCO-TURBT tool: a summative assessment tool that measures surgical competency in transurethral resection of bladder tumour. Surgical Endoscopy 32:12, 4923-4931. [Crossref]

12. Wesley Baas, Matthew Davis, Bradley F. Schwartz. Simulation in Surgery 439-488. [Crossref]

13. Amal Alsalamah, Rudi Campo, Vasilios Tanos, Gregoris Grimbizis, Yves Van Belle, Kerenza Hood, Neil Pugh, Nazar Amso. 2017. Face and content validity of the virtual reality simulator 'ScanTrainer ${ }^{\circledR}$ '. Gynecological Surgery 14:1. . [Crossref]

14. Leizl Joy Nayahangan, Rikke Bølling Hansen, Karen Gilboe Lindorff-Larsen, Charlotte Paltved, Bjørn Ulrik Nielsen, Lars Konge. 2017. Identifying content for simulation-based curricula in urology: a national needs assessment. Scandinavian Journal of Urology 51:6, 484-490. [Crossref]

15. Daniel Zainfeld, Siamak Daneshmand. 2017. Transurethral Resection of Bladder Tumors: Improving Quality Through New Techniques and Technologies. Current Urology Reports 18:5. . [Crossref]

16. Abdullatif Aydin, Nicholas Raison, Muhammad Shamim Khan, Prokar Dasgupta, Kamran Ahmed. 2016. Simulation-based training and assessment in urological surgery. Nature Reviews Urology 13:9, 503-519. [Crossref]

17. Abdullatif Aydin, Ahmed M.A. Shafi, Muhammad Shamim Khan, Prokar Dasgupta, Kamran Ahmed. 2016. Current Status of Simulation and Training Models in Urological Surgery: A Systematic Review. Journal of Urology 196:2, 312-320. [Crossref]

18. Oliver Brunckhorst, Alessandro Volpe, Henk van der Poel, Alexander Mottrie, Kamran Ahmed. 2016. Training, Simulation, the Learning Curve, and How to Reduce Complications in Urology. European Urology Focus 2:1, 10-18. [Crossref] 